\title{
The Principles in Green Design
}

\author{
Q.h. YUAN ${ }^{1, *}$ and L.y Tang ${ }^{2}$ \\ ${ }^{1}$ Guangdong University of Science \& Technology, Dongguan 523083, China \\ ${ }^{2}$ Guangdong University of Science \& Technology, Dongguan 523083, China
}

\begin{abstract}
Nowadays economic activities and lifestyles must be green according to Sustainable Development, so Green Design must be taken at the whole process of product life cycle. Now 3R principles (Reduce, Reuse, Recycle) is well-known for sustainable envelopment, but for the sake of accelerating green development, It should follows the 10R principles in green design: Reduce, Reuse, Recycle, Renew, Recharge(or Refill), Repair(or Remedy), Re-manufacture(or Recover), Replace(or Replant), Re-clear(or Refine) and Remove. The $10 \mathrm{R}$ principles can make green design at the first time to start green development. It is also the historical responsibility and obligation of contemporary designers.
\end{abstract}

\section{Introduction}

Since the 1960s, a series of public hazards, such as resource depletion, environmental pollution and ecological damage have occurred frequently, arousing people's concern and worry about the global crisis. Since then green and sustainable development has gradually become the basic consensus of the international community, and Green Design is thus developed. Published in 1971, American designer Papanek inappropriate at that time, but later influential book "designed for the real world - human ecology and social change", he proposes design cannot follow the market, meet the consumption, highly critical business society purely for the purpose of profit maximization of industrial design, put forward "design should have strict self-disciplinet", calling for designers to focus on and protecting resources and environment [1,2]. In 1979, AvrilFox and RobinMurrel formally proposed the concept of "Green Design"[3]. In the 1980s, the wave of "green consumption" rose in the United States, when The French designer Stark put forward the simple design concept of "less is better". Since 1990s, Green Design has become a hot issue in modern design research. In 2013, scholars advocating Green Design from China and the EU jointly established the "world Green Design organization" (WGDO) in Belgium, aiming to promote the concept of Green Design globally and lead the industrial, consumption and social transformation in the new era $[4,5]$.

\section{The definition and essence of Green Design}

Green Design, also is known as Design for Environment, Environment Conscious Design, Ecological design, and
Sustainable Design, Product Life Cycl eDesign, Low Carbon Design, etc[6-9]. The basic connotation of Green Design is: under the premise of satisfying functions $(\mathrm{F})$, quality $(\mathrm{Q})$, cost $(\mathrm{C})$, etc in product design, the whole cycle process control of products should be implemented to maximize resource utilization and minimize environmental pollution, so as to maximize the value $(\mathrm{F}+\mathrm{Q})$ and minimize the $\operatorname{cost}(\mathrm{C})[9]$. Green Design should not only focus on "human", but also respect nature, that is, strive for harmony between human and nature, symbiosis, and embody "unity of nature and man" [10]. Therefore, Green Design aims to achieve sustainable economic and social development. On the basis of a deep understanding of the relationship between man and nature, it carries out comprehensive innovation in various aspects in the whole process of traditional design, so as to realize the continuous utilization of natural resources, continuous improvement of ecological environment, continuous growth of production wealth and continuous improvement of life quality. The essence of Green Design is to seek the intersection of "natural green, economic green, social green and spiritual green" to maximize. It reflects the "nature-oriented" design theory, instead of the concepts of "machine -oriented"and "people-oriented" design theories[11].

\section{The principles of green design}

In order to realize the green and sustainable development of economic society, we must implement green design from the source. Because design is source of product research and development, production, consumption, circulation, recycling. At present, the $3 \mathrm{R}$ principles (Reduce, Reuse, Recycle) has become an internationally recognized basic principle of green design. In order to

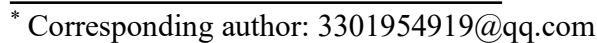


save energy, reduce consumption and reduce pollution in production and life in a more comprehensive way, green design must be considered from the whole process of product life cycle and the principles of $3 \mathrm{R}$ should be promoted to the principle of $10 \mathrm{R}$. In addition, the $10 \mathrm{R}$ principles should be followed at the beginning of the design, because design is the source of all product production and use. In order to realize the green production and use of products, the 10R principle should be used as the guide for green design to ensure the green of the whole process of the product life cycle from the source. The $10 \mathrm{R}$ principles in green product design are as follows:

\subsection{Reduce}

Refers to the use of appropriate methods to reduce the production and life of waste emissions, with less resources to achieve the established purposes of production and life, it is the most basic way to prevent and reduce environmental pollution. This requires in the design to do:

1.The design of the product obey the rule -suitable is good, the product performance parameters to determine the requirements of adaptability and portability, can not be blind to tall and complete. Design personalized products for different consumers, such as age, gender, occupation, education, etc.

2.Product design should be simple in everything, and strive for the simplest structure, process, packaging, etc. "good steel should be used on the blade", so as to achieve the "three low" principle of the least material, energy consumption and pollution [12]; The satisfaction design of a product has been reduced and cannot be reduced anymore, but by no means can be added and cannot be added anymore. This is not to cut corners, but to save under the premise of ensuring reliable product quality.

3.Design activities themselves should be frugal and efficient. For example, computer digital design (CAD), auxiliary analysis (CAE), CNC machining (CAM), virtual prototype (VR, AR), 3D printing, etc. Design is a link with high intensity and high consumption, while green design has higher requirements and higher consumption. According to statistics, green design determines the consumption of $80-90 \%$ in the product life cycle [13]. The design process of labor-saving materials, network coordination, efficient and fast is inevitable trend. Design to be efficient, but not careless or cut corners, a detail error and loopholes in design may lead to the subsequent production or cause of thousands of times the loss. For example, in recent years products frequently appear recall gate incident, how much is the loss? Therefore, the design is frugal and efficient in the method and means, but the quality and standard of the design must pursue perfection, rather than spend more than ten times the time polishing details, as far as possible to solve the problem in the design link, also leave no defects in the back.
To make products that can be reused many times, to make them durable enough to prevent them from going to waste too soon, as is the case with modern rocket recycling technology. This requires the following in the design:

1.The product is designed to be durable; To improve the reliability of reusable parts, manufacturers should try to extend the life of products and quality guarantee period, rather than frequent replacement.

2.Reusable parts are easy to be refurbished and tested to simplify the recycling process and improve the recycling value.

3.Avoid designing disposable products ; The cost performance of disposable products is the lowest, while the consumption of environmental pollution is the greatest, must be limited to use. For example, from 2000 to 2018 , the annual per Chinese capita express business volume increased from 0.01 to 36 . The total consumption of various express packaging materials increased from 20,600 tons to 9.41 million tons. Only less than 5\% of carton packaging waste was reused.

4.Product design strive for standardization, serialization, generalization and modularization. For example, in the past the charger interfaces of laptops and mobile phones were different and could not be matched. It was very inconvenient to charge. Later, the unified standard interface was adopted to be able to share the charging with each other.

\subsection{Recycle}

To recycle things by throwing away things again so that they become useful resources rather than things thrown away. There are two cases of recycling, one is primary recycling, that is, waste products are recycled to produce the same type of new product consumption [14]. Such as recycled paper; The other is secondary recycling, in which waste resources are converted into raw materials for other products, such as a mixture of various colored plastics to regenerate black plastic products. Primary recirculation is much more efficient than secondary recirculation, and can reduce the consumption of raw materials better, which is the optimal route of circular economy. In order to facilitate product recycling, it is required that:

1.parts of different materials can be easily separated, so as to facilitate the classification and recycling of all kinds of raw materials for resource reuse.

2.Strive to use recyclable and reused raw materials. 3.Avoid the use of non-recyclable raw materials, the use of toxic and harmful materials should be more cautious.

\subsection{Renew}

The materials and energy of products should be green and renewable. Only by selecting renewable, degradable and pollution-free green materials and green energy, resource-saving and environment-friendly design can be fully realized[15]. For example, There are solar electric vehicles, electric power generation, its development prospects are very broad.

\subsection{Reuse}


TRIZ and BioTRIZ are powerful tools that can effectively stimulate product creativity in green design $[16,17]$. Accordingly, it is important to establish a correlation table between environmental efficiency elements and engineering parameters (EP) [18], such as green materials and green energy. In addition, microbial processing technology can achieve zero energy consumption for processing or zero energy consumption for natural degradation.

\subsection{Rechargeable or Refill}

It require that the consumable or energy of a product be recharged or Refill after being used up. For example, Traditional launch vehicles are for one-time use. After launch, they fall back to the ground or burn out in the atmosphere, often leaving only a few metal fragments. But the vertical take-off and landing launch vehicles fall back to the ground. As long as it is repaired and refueled, it can be launched again[19]. Space exploration technology company was founded in 2002 by Elon Musk. Until now the Falcon 9 first-stage rocket has launched 103 times, successfully landed 64 times[20].Through Return+Repair+Refilling+Reuse, the rocket can be continuously recycled, which greatly reduces launch costs. It is also beneficial to protect the environment[21].

\subsection{Repair or Remedy}

It is required that the wearing parts of the product be easy to repair after damage. This requires that the product itself is easy to be disassembled during design, especially for the wearing parts. Now a lot of products in order to prevent imitation, deliberately designed into a non-removable sealing type, a tear down to scrap. Once in case of failure can only throw away, unable to repair, it is a pity! Only when it is easy to disassemble can be easy to repair, exchange, sort, recycle and reuse [22]. Therefore, in the design stage, the product structure must be fully considered for easy disassembly, that is, design for dis-assembly (DFD). The disassembly design criteria mainly include:

1.Product self-check function can be designed to realize rapid fault diagnosis and convenient maintenance.

2.Modular combination design, especially reusable or toxic components easy to disassemble.

3.Reduce the number of parts, simplify the structure of parts, simplify the manufacturing and recycling process.

4.Adopt universal materials to reduce the types of materials and reduce metal inserts of plastic parts.

5.Adopt standard parts, reduce the number of fasteners, and try to adopt the same fastening method.

6.Avoid aging damage of parts due to pollution and corrosion. toxic materials must be sealed.

\subsection{Re-manufacture or Recover}

Guided by the full life cycle design of products, aiming at the recovery and improvement of the performance of waste products, and guided by the principles of high quality, high efficiency, energy saving, material saving and environmental protection, the technology of repairing and transforming waste products [23,24]. Green remanufacturing design technology mainly includes:

1.Simplify the process and make the complex simple. For batch parts can provide mold, one-time molding, and the processing technology is minimized. Recently Tesla officially announced the 6,000-ton die-casting machine at the Shanghai Super Factory, which integrates the Model $\mathrm{Y}$ back plate into a whole. The weight is reduced, and the welding large-scale casting machine reduces the body from 70 parts to $1-2$ parts(Fig1) $[24,25]$.
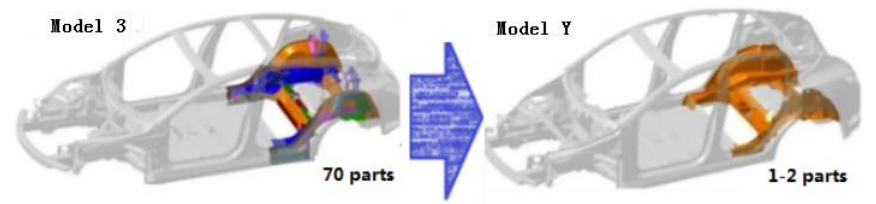

Fig. 1. Structure comparison of Model 3 and Model Y.

2.The performance of waste products is easy to detect and recover. For example the surface retreatment process can directly repair the old to new. Worn shafts and holes can be directly repaired to new ones through surface reprocessing processes such as electroplating 、 electrochemical machining(ECM) and laser machining[26].

3. Direct recovery of scrap products. If the part is not drilled with positioning holes or milling grooves before quenching, it can only be scrapped in the conventional processing technology, but it can be remedied by non-traditional machining methods such as electric spark $(E D M)$, electrochemical machining(ECM) 、 and 3D print[27].

4.Remanufacturing equipment and green process design, or Design for Remanufacturing-DfRem[28]. It means that in the process of mechanical equipment design, while meeting the normal functional requirements of mechanical equipment, the remanufacturability at the end of the life of the mechanical equipment must also be considered, and according to the remanufacturing indicators and requirements, it is designed to have good remanufacturability at the end of the life. DfRem is an important aspect of achieving green and low-carbon product manufacturing.

5. Remanufacturing quality control technology. Such as remanufacturing process on-line quality inspection and product quality inspection, for the sake of discovering problems in time, regulating equipment in time, and maximize product quality qualification rate. Nowadays many of the discarded Shared bikes have been piled up into mountains, forming large dumps. How to remanufacture the discarded Shared bikes has become a pressing issue.

\subsection{Replace or Replant}

It requires that all parts of the product and their input and output interfaces be universal, standardized, and interchangeable. This requires that 
1.Product standards should be as general as possible. For example, mobile phone chargers used to be interoperable, but later legislation was passed to mandate the use of a uniform standard interface, which ensured that mobile phone chargers from different companies could be interoperable.

2.Replace the consumable material design with the new energy-saving design. For example, a large TV set made by SONY uses 8 small pieces of split packaging to replace the previous integral packaging, which can reduce the foam plastic material by $40 \%$.

3.Try to add new functions that can be used in conjunction with other products while the product functions are independent. For example, The snow disaster in Texas this year caused large-scale water and power outages. Ford hybrid F-150 and Tesla Model 3 all have power generation function to avoid disasters.

\subsection{Re-clear or Refine}

It is required that the dirty parts of the product can be cleaned and purified for reuse, instead of being discarded once polluted. This is required in the design of the selection of detachable washing, cleaning scheme. Cleaning and refining is a process with high energy consumption, high pollution and high labor intensity. It includes preliminary cleaning before disassembly, detailed cleaning and refining after disassembly, and cleaning before packaging. The requirements and goals are different at different stages. The cleaning and refining process must be considered in the design process.

High-tech cleaning such as laser cleaning 、 electrochemical cleaning and ultrasonic cleaning can be used for non-destructive cleaning of precision parts and electronic components[29-33]. In order to facilitate cleaning, textures and geometric shapes that facilitate cleaning can be used, such as relatively flat surfaces, or materials with self-cleaning surface[34-36]. It is preferable to choose a cleaning method that requires fewer changes to complete the cleaning structure, which can simplify the cleaning process. The use of materials that require special cleaning methods should be avoided as much as possible to minimize cleaning costs and waste generation. For example, nowadays water purifier, air purifier and other general use of activated carbon particles filtration, once the adsorption saturation, activated carbon will lose the adsorption dirt activity, can only be replaced, can not be cleaned, the cost of replace is too expensive. If the use of activated carbon fiber, after cleaning, can be repeated use, so that can greatly reduce the cost and waste of the purifier.

\subsection{Remove}

Since industrialization, humans have discharged a large amount of garbage, waste water and exhaust gas, which has destroyed the ecological environment balance. These three industrial wastes should be removed as clean as possible. For example, $\mathrm{CO}_{2}$ concentrations in the atmosphereis $280 \mathrm{ppm}$ before the industrial Revolution. It is now at $407.8 \pm 0.1 \mathrm{ppm}$ [37]. Removing $\mathrm{CO}_{2}$ is an important part of achieving low-carbon emissions reduction. The current methods are as follows:

1.Carbon Capture and Storage(CCS), Including 3 basic processes of $\mathrm{CO}_{2}$ capture, transportation and storage. It refers to the separation of $\mathrm{CO} 2$ from industrial production or energy conversion process, and transport to the storage site after compression, and injection into the ocean or deep underground rocks to isolate it from the atmosphere for a long time. CCUS is a new development trend of CCS technology, that is to purify the $\mathrm{CO}_{2}$ emitted during the production process, and then put it into a new production process, which can be recycled and reused instead of simply being sealed, so it is more practical[38]. 2.Direct Air Capture(DAC), that is to capture $\mathrm{CO}_{2}$ directly from the air. It can alleviate climate change, and the captured $\mathrm{CO}_{2}$ can be used to transfer low-carbon synthetic fuels (A2F).

3.Biomass Energy for Carbon Capture and Storage (BECCS), that is to use biomass to generate renewable energy. Biomass is formed or derived through photosynthesis and absorbs $\mathrm{CO}_{2}$ from the atmosphere. The biomass is then processed into green fuel.

\section{Conclusion}

The 10R principles should be followed in the process of green design, which must be comprehensively considered and flexibly applied(Fig3). In this way new products can been designed more green and environmentally friendly, save money and reduce consumption, and make green design at the first time to start green development. It is also the historical responsibility and obligation of contemporary industrial designers. The basic point of green design is environmental protection and energy conservation.

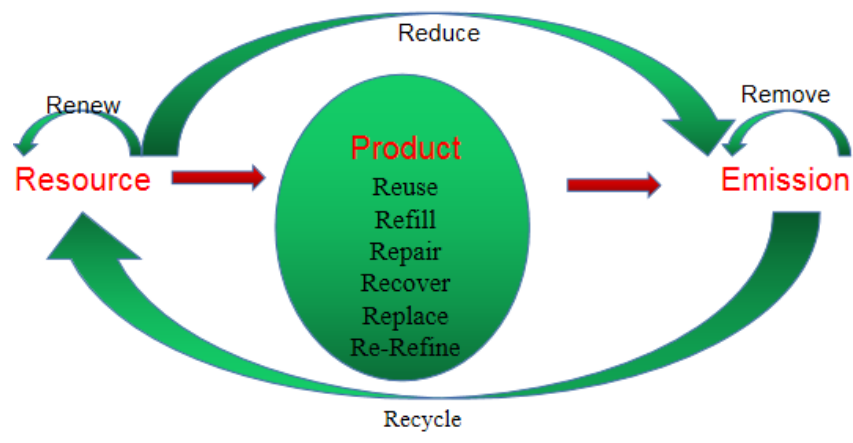

Fig. 2. The $10 \mathrm{R}$ principles in green design

Thank GDST Research Foundation (GKY-2019KYYB-21) for support of the study.

\section{References}

1. Niu wenyuan. Green design is the first lever to launch green development. Journal of Chinese academy of sciences.2016,31(5):491-498. DOI:10.16418/j.issn.1000-3045.2016.05.001.

2. Papanek V. Design for the Real World. Chicago: Academy Chicago Publishers, 1985. 203-205. 
3. Fox A, Murrell R. Green Design: A Guide to the Environmental Impact of Materials. London: Phaidon Press, 1989: 126-129.

4. Fiksel J. Design for Environment: An integrated systems approach. Arlington: 1ST IEEE international symp on electronics and the environment. 1993: 126-131.

5. Niu Wenyuan.2016 China Green Design Report [M]. Beijing: Science Press,2016.

6. Bhamra, T.; Lofthouse, V. Design for Sustainability; Gower Publishing Ltd. Aldershot, UK, 2007.

7. Faludi, J.Golden, Tools in Green Design: What Drives Sustainability, Innovation, and Value in Green Design Methods? University of California: Berkeley, CA, USA, 2017.

8. McMahon, M.; Bhamra, T. Social Sustainability in Design: Moving the Discussions Forward. Design Journal.2015(18):367-391.DOI $10.1080 / 14606925.2015 .1059604$.

9. Kees Dorst,The core of 'design thinking' and its application,Design Studies,2011,32(6) : 521-532, https://doi.org/10.1016/j.destud.2011.07.006.

10. Guo Xuanchang, JIANG Haiqing. Rethinking green Design through the thought of Unity of man and nature. Ecological Economy.2016,32(08):224-227.

11. Liu Hengli,; Liu Baoshun, (2011).[IEEE 2011 International Symposium on Water Resource and Environmental Protection (ISWREP) - Xi'an (2011.5.20-2011.5.22)]. Rethinking of green design and environmental protection, 2280-2281. DOI : 10.1109/iswrep.2011.5893721.

12. Sianne Gordon-Wilson, Pratik Modi ,Personality and older consumers' green behaviour in the UK,Futures, 2015,71(5):1-10, DOI:https://DOI.org/10.1016/j.futures.2015.05.002.

13. Du Juanjuan. On Green Design under Circular Economy. Wuhan: Wuhan Textile University,2016.

14. Cao Shaozhong, TU Xu-yan, Yang Guo-wei.Green circular Economy and Green Design. Mechanical Design,2004(04):1-5.DOI 10.13841/j.cnki.jxsj.2004.04.001.

15. He, Can Qun, and Bo Ji. The Material Selection in Green Design. Key Engineering Materials, vol. 474476, Trans Tech Publications, Ltd., Apr. 2011, pp. $1551-1556$. DOI 10.4028/www.scientific.net/kem.474-476.1551.

16. Ben Moussa, F.Z.; Essaber, F.E.; Benmoussa, R.; Dubois, S. Enhancing Eco-Design Methods Using TRIZ Tools: The Case of ECOFAIRE. In New Opportunities for Innovation Breakthroughs for Developing Countries and Emerging Economies. TFC 2019,572. IFIP Advances in Information and Communication Technology;

17. Zhonghang Bai.Lei MuGreen Product Design Based on the BioTRIZ Multi-Contradiction Resolution Method.Sustainability.2020,12(10), 4276; DOI: https://doi.org/10.3390/su12104276.
18. Ekmekci, I. Koksal, M. Triz Methodology and an Application Example for Product Development.Procedia Soc. Behav. Sci.2015,195, 2689-2698.

19. Space Launch Report: SpaceX Falcon Data Sheet, http://www.spacelaunchreport.com/falcon9.html.

20. falcon-9.https://www.spacex.com/vehicles/falcon-9/.

21. The greatest project in human history PPT, Musk's 39-page Mars Project PPT. https://www.sohu.com/a/441679082_659777.

22. CHEN Wei-hua. The Concept of the Green Mechanical Products Design. Journal of Industrial Design, 2012 (1): 2-22.

23. LI Cong-bo. Green Manufacturing Operation Mode and its Implementation Method Research. Chongqing: Chongqing University, 2009.

24. Wang Qingfeng;Gao Jinji et al. Theoretical research and application of equipment in-service remanufacturing engineering .Chinese Journal of Mechanical Engineering.2018,54(22):1-7.DOI : 10.3901/JME.2018.22.001.

25. Sohu, Tesla's integrated die-casting machine is coming, reducing from 70 parts to 1 ? https://www.sohu.com/a/449024568_99957845.

26. Liu Jinchun, Bai Jicheng, Guo Yongfeng, and Yang Xiaodong, "Non-Traditional Machining" (6th Edition). Beijing: Machinery Industry Press, May 2013.

27. Xia Juchen, $\mathrm{Hu}$ Hongbin, Zhao Haitao.et al.Development and application on 3D printing manufacturing and remanufacturing technology and equipment for hot forging mold. FORGING \& STAMPING TECHNOLOGY.2020(08),1-5. DOI:10.13330/j.issn.1000-3940.2020.08.001.

28. Gong Qingshan. Research on Remanufacturing-Oriented Multi-Objective Optimization Design of Mechanical Equipment. Wuhan : Wuhan University of Science and Technology.2019.

29. Wang Sijie, Qiao Yulin, Liu Pengfei \& Liu Zhaowei. Advanced laser cleaning technology and its application for equipment remanufacturing. Material development and application. 2019(05),77-82. DOI:10.19515/j.cnki.1003-1545.2019.05.016.

30. Liu Xiaomin, et al. "Innovative design of self-cleaning glass integrating bionics and extenics." Chinese Journal of Engineering Machinery.2019.17(04):323-328+334. DOI:10.15999/j.cnki.311926.2019.04.007.

31. Chen Penghui. Research on hydrophilic self-cleaning film on the surface of photovoltaic panels. Nanchang: Nanchang University. 2019.

32. Jiang Nan. Preparation and characterization of high-performance anti-ultraviolet self-cleaning glass coating. Shanghai: East China University of Science and Technology.2018. 
33. Li Lu, et al. Research Progress in the Application of Ultrasonic Cleaning Technology in the Industrial Field. Applied Chemical Industry.2020(12):. DOI:10.16581/j.cnki.issn1671-3206.20201221.017.

34. Zhang Dongjiu,Wu Guoqing. et al. Superamphiphobic surfaces with robust self-cleaning, abrasion resistance and anti-corrosion. Chemical Engineering Journal,2021,406.

DOI:10.1016/J.CEJ.2020.126753.

35. Mandal Priya,Perumal Gopinath, et al. Green manufacturing of nanostructured Al-Based sustainable self-cleaning metallic surfaces. Journal of Cleaner Production,2021,278.

DOI:10.1016/J.JCLEPRO.2020.123373.

36. Xu Peimin, et al. Design Improvement of Steel Wire Continuous Electroplating Machine. Electroplating and Finishing.2020(21).39:1474-1476. DOI:10.19289/j.1004-227x.2020.

37. Maarten Kappelle.WMO Statement on the State of the Global Climate in 2019. https://www.researchgate.net/publication/340135130 _WMO Statement on the State of the Global Climate in 2019. DOI: $10.13140 /$ RG.2.2.13705.19046.

38. Gao Hua. Global Carbon Capture and Storage (CCS) Technology Status and Application Prospects. Coal Economic Research.2020.40.(05):33-38. DOI : 10.13202/j.cnki.cer.2020.05.005. 